EL MUHASABA: Jurnal Akuntansi (e-Journal)

Volume 12 , No. 1, Tahun 2021

P ISSN: 2086-1249; E ISSN: 2442-8922

\title{
SLIPPERY SLOPE FRAMEWORK: MOTIVASI PEMBAYARAN PAJAK DAN KEPATUHAN PAJAK
}

\author{
Firda Ayu Amalia \\ Universitas Muhammadiyah Malang \\ Jalan Raya Tlogomas No. 246 Malang, Jawa Timur, Indonesia \\ e-mail: firdaayu@umm.ac.id
}

\section{Abstract}

The purpose of this study is to provide empirical evidence behind tax compliance based on a slippery slope framework, namely the motivation to pay taxes due to the power (power) of the government or the awareness of the taxpayers themselves. This study uses a quantitative descriptive approach with data collection techniques in the form of questionnaires and interviews. The sample used was the UMKM actors in Batu's city with a purposive sampling technique. The study results provide empirical evidence that tax payment motivation has a positive effect on tax compliance. Furthermore, interviews with several MSME actors who became respondents stated that tax payments were based on the government's power. It can be said that the motivation for tax payments has not been based on the taxpayer's awareness. The research results are expected to provide advice to the government regarding policies or steps that should be taken to increase the trust (trust) of taxpayers on tax payments that have been made. If the trust is built, tax compliance can increase without coercion.

Keywords: Tax compliance; Tax payment motivation; Power; Slippery slope framework; Trust

\section{Abstrak}

Tujuan penelitian ini adalah memberikan bukti empiris yang melatarbelakangi kepatuhan pajak didasarkan dengan slippery slope framework, yaitu motivasi membayar pajak karena adanya kekuasaan (power) dari pemerintah atau atas kesadaran dari wajib pajak itu sendiri. Penelitian ini menggunakan pendekatan deskriptif kuantitatif dengan teknik pengumpulan data berupa kuesioner dan wawancara. Sampel yang digunakan adalah pelaku UMKM yang berada di kota Batu dengan teknik purposive sampling. Hasil penelitian memberikan bukti empiris yaitu motivasi pembayaran pajak berpengaruh positif terhadap kepatuhan pajak. Selanjutnya hasil wawancara terhadap beberapa pelaku UMKM yang menjadi responden menyatakan bahwa pembayaran pajak didasarkan oleh power yang dimiliki oleh pemerintah. Dapat dikatakan bahwa motivasi pembayaran pajak belum didasarkan atas kesadaran wajib pajak. Hasil penelitian diharapkan dapat memberi saran kepada pemerintah mengenai kebijakan ataupun langkah yang seharusnya dapat dilakukan dalam rangka meningkatkan kepercayaan (trust) dari para wajib pajak atas pembayaran pajak yang telah dilakukan. Apabila trust sudah terbangun maka kepatuhan pajak dapat meningkat tanpa adanya paksaan. 
Firda Ayu Amalia : Slippery Slope Framework: Motivasi Pembayaran Pajak Dan Kepatuhan Pajak

Kata Kunci: Kepatuhan pajak,; Motivasi pembayaran pajak; Power; Slippery slope framework; Trust

\section{PENDAHULUAN}

Kepatuhan pajak oleh Usaha Mikro Kecil dan Menengah di Indonesia masih rendah (Fauziah \& Tidajoh, 2018). Dikutip dari berita Kompas tanggal 30 April 2019, jumlah UMKM yang terdapat di Indonesia sekitar 59 juta pada akhir 2018 akan tetapi yang terdaftar sebagai wajib pajak hanya sekitar 1,8 juta (Movanita, 2019). Rendahnya kepatuhan pajak oleh UMKM juga diperkuat oleh bukti bahwa penerimaan pajak dari sektor UMKM hanya berkontribusi sebesar $0,43 \%$ (Kemenkeu, 2018). Sebenarnya potensi penerimaan negara dapat meningkat apabila seluruh UMKM yang ada mendaftarkan dirinya sebagai wajib pajak. Direktorat Jendral Pajak (DJP) menjelaskan bahwa penerimaan pajak dari wajib pajak pelaku UMKM masih jauh dari kondisi yang seharusnya (DJP, 2018).

Rendahnya kepatuhan pajak pelaku UMKM juga diperkuat dengan diubahnya aturan mengenai tarif pajak UMKM. Pemerintah menerbitkan PP. No. 23 tahun 2018 tentang Pajak Penghasilan atas Penghasilan Usaha yang Diterima atau Diperoleh Wajib Pajak yang Memiliki Peredaran Bruto dibawah 4,8 miliar setahun. Tujuan penerbitan PP tersebut adalah agar pelaku UMKM tidak merasa keberatan dalam membayar pajak. Hal ini dikarenakan tarif pajak dalam PP. No. 23 tahun 2018 lebih rendah jika dibandingkan tarif pajak pada peraturan sebelumnya., yaitu hanya $0,5 \%$ dari peredaran bruto setahun. Peraturan sebelumnya pada PP. No. 46 tahun 2013 mengatur tarif pajak bagi UMKM sebesar $1 \%$ dari peredaran bruto setahun dan hal ini dirasa berat bagi pelaku UMKM, terlebih jika pelaku UMKM mengalami kerugian usaha (SULARSIH, 2018).

Fenomena yang telah dijelaskan tersebut membuktikan bahwa kepatuhan pajak pelaku UMKM masih rendah. Simanjuntak and Sucipto (2018) menjelaskan bahwa rendahnya kepatuhan pajak disebabkan oleh motivasi untuk membayar pajak atau kesadaran akan kewajiban membayar pajak masih rendah. Selanjutnya, Abdullah and Nainggolan (2018) menjelaskan bahwa salah satu faktor penting yang mempengaruhi kepatuhan pajak adalah kesadaran dan motivasi dari wajib pajak itu sendiri. Motivasi merupakan suatu hal yang mendasari seseorang melakukan suatu perbuatan (Cimberly, Manossoh, \& Wokas, 2018). Motivasi yang tinggi dipengaruhi oleh persepsi positif seseorang terhadap suatu hal. Abdullah and Nainggolan (2018) menjelaskan bahwa motivasi membayar pajak oleh wajib pajak sangat penting dilakukan agar dapat memberikan gambaran secara jelas mengenai fenomena yang sesunggguhnya terjadi dimasyarakat. Berdasarkan penjelasan tersebut, peneliti ingin mengaitkan motivasi membayar pajak oleh para pelaku UMKM dengan kepatuhan pajak.

Penelitian mengenai motivasi membayar pajak dan kepatuhan pajak telah diteliti oleh beberapa penelitian terdahulu (Abdullah \& Nainggolan, 2018; Cimberly et al., 2018; Dalimunthe, 2018; Simanjuntak \& Sucipto, 2018). Sebagian 
Firda Ayu Amalia : Slippery Slope Framework: Motivasi Pembayaran Pajak Dan Kepatuhan Pajak

besar sampel yang digunakan oleh penelitian terdahulu adalah wajib pajak orang pribadi. Penelitian terdahulu memberikan hasil yang konsisten yaitu motivasi membayar pajak berpengaruh positif terhadap kepatuhan pajak. Akan tetapi dalam penelitian terdahulu tidak membahas lebih lanjut mengenai motivasi pembayaran pajak dengan kerangka slippery slope.

Novelty dalam penelitian ini adalah peneliti mengaitkan motivasi pembayaran pajak dengan kerangka slippery slope atau slippery slope framework yang dikemukakan oleh (Kirchler, Hoelzl, \& Wahl, 2008). Dalam penelitiannya, (Kirchler et al., 2008) menggunakan framework slippery slope untuk membuktikan pengaruh kekuasaan pemerintah dan kepercayaan masyarakat pada kepatuhan yang bersifat terpaksa dan kepatuhan pajak yang bersifat sukarela. Pemerintah memiliki kekuasaan berupa peraturan yang didalamnya terdapat sanksi untuk memaksa wajib pajak agar patuh membayar pajak. Berbeda dengan kepatuhan pajak yang bersifat paksaan, kepatuhan pajak sukarela berasal dari diri wajib pajak itu sendiri. Kepatuhan sukarela oleh wajib pajak dapat terbentuk jika wajib pajak percaya pada pemerintah.

Selain itu, novelty dalam penelitian ini adalah berupa penggunaan istilah yang berbeda. Dalam framework slippery slope yang dikemukakan oleh (Kirchler et al., 2008) istilah yang digunakan adalah motivasi membayar pajak karena keterpaksaan atau kesukarelaan. Dalam penelitian ini, selain menguji empiris pengaruh motivasi pembayaran pajak terhadap kepatuhan pajak berdasarkan hasil uji kuesioner, peneliti juga melakukan wawancara lebih lanjut untuk memberikan bukti terkait motivasi membayar pajak dalam hubungannya dengan slippery slope framework. Penelitian yang telah dilakukan sebelumnya hanya berupa pengujian asosatif, membuktikan secara empiris pengaruh kepercayaan pada pemerintah dan sanksi pajak terhadap kepatuhan pajak (Dalimunthe, 2018)(Simanjuntak \& Sucipto, 2018).

Tujuan penelitian ini adalah membuktikan secara empiris kepatuhan pajak yang didasarkan pada slippery slope framework terkait motivasi pembayaran pajak oleh wajib pajak yaitu pelaku UMKM di kota Batu. Slippery slope framework menjelaskan motivasi pembayaran pajak atas dasar kekuasaan (power) dari pemerintah atau karena kesadaran yang timbul atas trust kepada pemerintah. Kontribusi penelitian ini diharapkan dapat memberikan bukti empiris pengaruh motivasi pembayaran pajak terhadap kepatuhan pajak. Selain itu penelitian ini juga memberikan kontribusi berupa motivasi pembayaran pajak oleh wajib pajak apakah atas dasar kesadaran atau karena adanya power dari pemerintah yaitu berupa sanksi apabila tidak memenuhi kewajiban pembayaran pajak.

\section{KAJIAN PUSTAKA}

\section{Slippery Slope Framework}

Kastlunger, Lozza, Kirchler, and Schabmann (2013) menjelaskan bahwa terdapat dua hal yang melatarbelakangi kepatuhan pajak apabila didasarkan 
Firda Ayu Amalia : Slippery Slope Framework: Motivasi Pembayaran Pajak Dan Kepatuhan Pajak

dengan slippery slope framework. Konsep slippery slope framework menjelaskan bahwa wajib pajak patuh membayar pajak karena terdapat kekuasaan (power) dari pemerintah atau karena wajib pajak tersebut memiliki kesadaran untuk patuh pajak. Pemerintah selaku pembuat kebijakan memiliki power, misalnya pengaturan tentang tarif pajak, sanksi pajak maupun denda administrasi (Mangoting \& Sadjiarto, 2013). Berbeda dengan power dari pemerintah, kesadaran membayar pajak yang berasal dari diri wajib pajak juga salah satu faktor yang dapat meningkatkan kepatuhan pajak. Mas' ud, Abd Manaf, and Saad (2019) menyebutkan bahwa kesadaran dapat timbul dari diri wajib pajak apabila terdapat trust atau kepercayaan terhadap pemerintah atas penggunaan uang pajak secara bertanggung jawab. Dalam penelitian ini untuk mengetahui motivasi membayar pajak atas kesadaran atau karena power yang dimiliki pemerintah, peneliti menggunakan metode wawancara kepada para responden.

\section{Kepatuhan Pajak}

Mustofa (2016) mendefinisikan kepatuhan pajak merupakan segala hal yang dilakukan oleh wajib pajak dalam rangka pemenuhan kewajiban perpajakan dengan baik dan benar. Kepatuhan pajak juga didefinisikan sebagai perilaku seseorang untuk memenuhi kewajiban perpajakan mulai dari menyetorkan, dan melaporkan pajaknya kepada otoritas pajak (Khasanah, Sutrisno, \& Mardiati, 2019). Berdasarkan penjelasan tersebut maka kepatuhan pajak adalah segala tindakan yang dilakukan oleh wajib pajak dalam rangka pemenuhan kewajiban perpajakan sesuai dengan ketentuan perpajakan.

\section{HIPOTESIS}

Simanjuntak and Sucipto (2018) mendefinisikan kepatuhan pajak sebagai hal yang memotivasi seseorang untuk melaksanakan atau tidak melaksanakan segala hal yang telah diatur dalam peraturan perpajakan. Salah satu faktor yang menyebabkan seseorang patuh atau tidak patuh adalah motivasi (Dalimunthe, 2018). Terdapat faktor psikologi yang mempengaruhi motivasi pembayaran pajak yaitu kekuasaan (power) dari pemerintah dan trust atau kepercayaan dari wajib pajak kepada pemerintah (Damayanti \& Martono, 2018). Dua faktor psikologi ini dikenal dengan slippery slope framework yang dikembangkan oleh (Kirchler et al., 2008). Beberapa penelitian terdahulu telah memberikan bukti empiris bahwa motivasi pembayaran pajak berpengaruh positif terhadap kepatuhan pajak. Dalimunthe (2018) menguji motivasi pembayaran pajak terhadap kepatuhan pajak dengan responden wajib pajak orang pribadi di KPP Pratama Medan Belawan. Hasil pengujian yang dilakukan oleh Simanjuntak and Sucipto (2018) juga memberikan hasil yang sama. Semakin tinggi motivasi untuk membayar pajak dari wajib pajak maka semakin tinggi juga kepatuhan pajaknya. Berdasarkan kerangka slippery slope dan hasil-hasil penelitian terdahulu maka peneliti merumuskan hipotesis sebagai berikut:

H1: Motivasi pembayaran pajak berpengaruh positif terhadap kepatuhan pajak 
Firda Ayu Amalia : Slippery Slope Framework: Motivasi Pembayaran Pajak Dan Kepatuhan Pajak

\section{METODE}

Penelitian ini merupakan penelitian deskriptif kuantitatif dengan tujuan untuk memberikan bukti empiris mengenai motivasi pembayaran pajak terhadap kepatuhan pajak.

Selanjutnya, hasil secara empiris tersebut akan dikuatkan oleh hasil deskriptif berupa wawancara.Populasi dalam penelitian ini adalah pelaku UMKM di kota Batu tahun 2020. Sampel yang diperoleh sebanyak 46 responden. Pengambilan sampel menggunakan teknik purposive sampling, dengan kriteria: 1). Pelaku UMKM yang kena pajak, 2). Pelaku UMKM membayar pajak melakukan pembayaran pajak secara langsung (tanpa diwakilkan) dan 3). Pelaku UMKM memiliki tingkat pendidikan minimal Strata 1.

Variabel dependen dalam penelitian ini adalah kepatuhan pajak. Kepatuhan pajak merupakan semua hal yang dapat mendorong seseorang maupun organisasi untuk berbuat atau tidak berbuat sesuai dengan peraturan perpajakan (Simanjuntak \& Sucipto, 2018). Indikator kepatuhan pajak mengacu pada (Tatik, 2018), yaitu pendaftaran wajib pajak, penghitungan dan pembayaran SPT, serta pelaporan SPT. Variabel independen yang digunakan adalah motivasi pembayaran pajak. Cimberly et al. (2018) mendefinisikan motivasi pembayaran pajak sebagai segala hal yang mendasari seseorang untuk memenuhi kewajibannya sebagai wajib pajak. Indikator yang digunakan untuk mengukur motivasi pembayaran pajak merujuk pada (Caroko, 2015), terdiri dari pengetahuan pajak, kualitas pelayanan pajak, sanksi pajak dan kesadaran diri.

Penelitian ini menggunakan teknik pengumpulan data berupa kuesioner dan wawancara. Peneliti menggunakan kuesioner tertutup dengan 5 point skala likert. Selanjutnya teknik pengumupulan data berupa wawancara ditujukan untuk mengonfirmasi jawaban responden berdasarkan kuesioner dan menggali lebih dalam tentang motivasi pembayaran pajak dalam kaitannya dengan slippery slope framework. Alat statistik yang digunakan untuk menguji pengaruh motivasi pembayaran pajak terhadap kepatuhan pajak adalah SmartPLS. Hal ini dikarenakan variabel motivasi pembayaran pajak dan kepatuhan pajak merupakan variabel laten. Langkah-langkah dalam menguji data menggunakan SmartPLS adalah uji kualitas data (outer model) dan uji struktural (inner model).

\section{HASIL DAN PEMBAHASAN}

\section{Uji Kualitas Data}

Sebelum dilakukan pengujian struktural untuk mengetahui hipotesis diterima atau ditolak, sebelumnya dilakukan pengujian kualitas data (outer model) terlebih dahulu. Kualitas data diuji dengan menggunakan uji reliabilitas dan uji validitas. Tujuan dilakukanya uji reliabel adalah untuk mengukur suatu kuesioner yang merupakan indikator dari varibel. Selanjutnya adalah uji validitas digunakan untuk mengukur sah atau valid tidaknya suatu kuesioner yang dibuat sebagai bahan penelitian (Ghozali \& Latan, 2015). 
Firda Ayu Amalia : Slippery Slope Framework: Motivasi Pembayaran Pajak Dan Kepatuhan Pajak

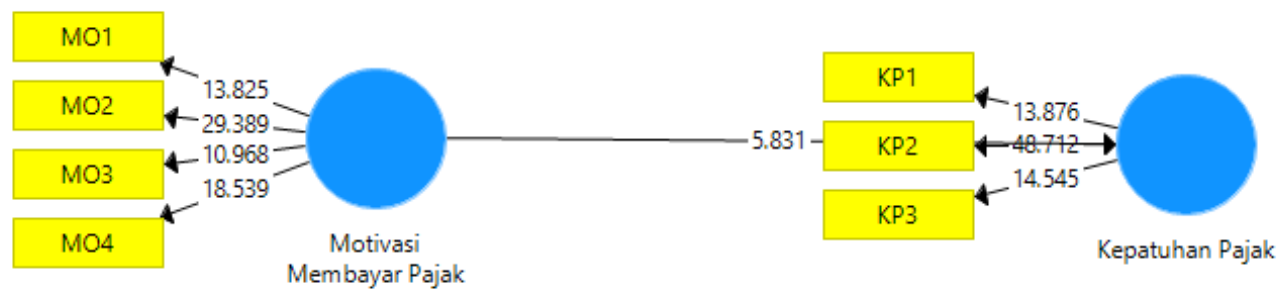

Tabel 1. Hasil Uji Validitas dan Reliabilitas

\begin{tabular}{llll}
\hline Keterangan & $\begin{array}{l}\text { Cronbach's } \\
\text { Alpha }\end{array}$ & $\begin{array}{l}\text { Composite } \\
\text { Reliability }\end{array}$ & AVE \\
\hline Kepatuhan Pajak & 0,859 & 0,914 & 0,781 \\
\hline $\begin{array}{l}\text { Motivasi Membayar } \\
\text { Pajak }\end{array}$ & 0,872 & 0,878 & 0,724 \\
\hline
\end{tabular}

Tabel 2. Hasil Uji Outer Loading

\begin{tabular}{|c|c|c|c|}
\hline Keterangan & Kepatuhan Pajak & $\begin{array}{l}\text { Motivasi } \\
\text { Pajak }\end{array}$ & Membayar \\
\hline KP1 & 0,872 & & \\
\hline KP2 & 0,940 & & \\
\hline KP3 & 0,836 & & \\
\hline MO1 & & & \\
\hline MO2 & & & \\
\hline $\mathrm{MO} 3$ & & & \\
\hline $\mathrm{MO} 4$ & & & \\
\hline
\end{tabular}

Tabel 1 dan tabel 2 menyajikan hasil uji validitas (nilai AVE dan loading) dan reliabilitas (cronbach's alpha dan composite reliability). Menggunakan metode cronbach's alpha, suatu konstruk dikatakan reliabel apabila nilainya >0,6. Apabila menggunakan composite reliability, suatu konstruk dikatakan reliabel apabila nilainya $>0,7$ meskipun nilai 0,6 masih dapat diterima (Hartono \& Abdillah, 2009). Berdasarkan ketentuan tersebut, maka data penelitian telah memenuhi syarat reliabilitas. Selanjutnya untuk uji validitas dapat dilihat dari nilai AVE dan nilai loading. Nilai AVE harus $>0,5$ dan nilai loading harus $>0,7$. Nilai AVE yang disajikan dalam tabel 1 variabel kepatuhan pajak dan motivasi pembayaran pajak, keduanya memiliki nilai AVE $>0,5$ dan juga nilai loading $>0,7$. Dapat dikatakan bahwa data penelitian telah memenuhi syarat uji validitas.

\section{Kepatuhan Pajak Ditinjau dari Slippery Slope Framework}

Setelah memenuhi uji kualitas data (uji outer model), pengujian dapat dilanjutkan ke uji inner model. Nilai R square adjusted sebesar 0,334, artinya motivasi pembayaran pajak dapat memprediksi model kepatuhan pajak sebesar $33,4 \%$. Selanjutnya untuk hasil uji hipotesis disajikan pada tabel 3. 
Firda Ayu Amalia : Slippery Slope Framework: Motivasi Pembayaran Pajak Dan Kepatuhan Pajak

Tabel 3. Hasil Uji Hipotesis

\begin{tabular}{llll}
\hline Keterangan & T statistic & P Value & $\begin{array}{l}\text { Keputusan } \\
\text { Hipotesisi }\end{array}$ \\
\hline $\begin{array}{l}\text { Motivasi } \\
\text { Pembayaran Pajak }\end{array}$ & 5,831 & 0,000 & Diterima \\
$\rightarrow$ Kepatuhan Pajak & & & \\
\hline
\end{tabular}

Berdasarkan hasil uji hipotesis pada tabel 3, dapat dilihat bahwa motivasi pembayaran pajak berpengaruh positif terhadap kepatuhan pajak. Hal ini dibuktikan dengan nilai signifikasi sebesar 0,000 $(<0,05)$ dengan arah atau tanda positif. Dapat dikatakan bahwa ketika wajib pajak memiliki motivasi pembayaran pajak yang semakin besar maka tingkat kepatuhan pajak pun semakin meningkat, demikian juga sebaliknya.

Hasil penelitian ini sejalan dengan hasil penelitian terdahulu (Dalimunthe, 2018; Septyani, Sudiartana, \& Mahaputra, 2020; Simanjuntak \& Sucipto, 2018). Septyani et al. (2020) menguji pengaruh motivasi pembayaran pajak yang digambarkan dengan variabel kualitas pelayanan, pemahaman wajib pajak dan penurunan tarif pajak penghasilan final terhadap kepatuhan pajak. Penelitian ini mengambil sampel sebanyak 100 UMKM yang terdaftar di KPP Denpasar Barat dan KPP Denpasar Timur tahun 2018. Hasil penelitian membuktikan bahwa motivasi pembayaran pajak (kualitas pelayanan, pemahaman wajib pajak dan penurunan tarif pajak penghasilan final) berpengaruh positif terhadap kepatuhan pajak.

Sejalan dengan hasil penelitian yang sekarang dilakukan, Dalimunthe (2018) juga menguji persepsi yang baik dari wajib pajak, motivasi dan sanksi terhadap kepatuhan pajak. Apabila dikaitkan dengan slippery slope framework, persepsi yang baik merupakan motivasi pembayaran pajak yang bermuara pada trust. Sanksi merupakan motivasi yang bermuara pada power yang dimiliki oleh pemerintah. Sampel yang digunakan sebanyak 100 responden wajib pajak orang pribadi dengan teknik convenience dan accidental sampling. Hasil penelitian membuktikan bahwa persepsi yang baik dari wajib pajak, motivasi dan sanksi berpengaruh positif terhadap kepatuhan pajak. Dapat dikatakan bahwa motivasi yang berasal dari kesadaran maupun karena adanya power dari pemerintah dapat meningkatkan kepatuhan pajak.

Selanjutnya peneliti melakukan wawancara kepada beberapa pelaku UMKM yang bersedia sebagai responden. Tujuan dilakukannya wawancara adalah untuk mengetahui lebih dalam terkait motivasi pembayaran pajak apakah atas kesadaran yang muncul karena adanya trust kepada pemerintah atau karena adanya kekuasaan atau power dari pemerintah. Dari 10 responden yang bersedia diwawancara, 8 responden menjelaskan bahwa motivasi pembayaran pajak adalah karena takut terkena sanksi pajak. Alasan lain yang memotivasi pelaku UMKM membayar pajak adalah adanya penurunan tarif pajak, semula 1\% dari peredaran bruto sekarang menjadi 0,5\% dari peredaran bruto. Dapat dikatakan 
Firda Ayu Amalia : Slippery Slope Framework: Motivasi Pembayaran Pajak Dan Kepatuhan Pajak

bahwa para pelaku UMKM di kota Batu memiliki motivasi membayar pajak karena adanya power dari pemerintah.

Hasil wawancara ini sejalan dengan hasil penelitian (Kastlunger et al., 2013). Kastlunger et al. (2013) menguji kekuasaan (power) pemerintah dan trust dari para wajib pajak terhadap kepatuhan pajak dengan menggunakan slippery slope framework. Sampel penelitian sebanyak 389 wajib pajak di Italia. Hasil penelitian membuktikan bahwa power dari pemerintah berkorelasi positif terhadap kepatuhan pajak. Kepatuhan pajak meningkat karena adanya paksaan peraturan perpajakan dari pemerintah Italia. Semakin meningkatnya kepatuhan pajak maka penerimaan negara dari pajak juga semakin meningkat. Akan tetapi hal ini juga dapat menimbulkan dampak negatif. Apabila motivasi pembayaran pajak didasarkan karena adanya power dari pemerintah, bukan atas dasar kesadaran maka kemungkinan akan terjadi peningkatan penghindaran pajak.

\section{KESIMPULAN}

Berdasarkan hasil pengujian yang dilakukan, motivasi pembayaran pajak berpengaruh positif terhadap kepatuhan pajak. Semakin tinggi motivasi pembayaran pajak dapat meningkatkan kepatuhan pajak. Motivasi pembayaran pajak dalam penelitian ini dikaitkan dengan slippery slope framework, yaitu atas dasar power dari pemerintah atau karena adanya trust kepada pemerintah. Dapat disimpulkan bahwa motivasi pembayaran pajak didasarkan atas power dari pemerintah. Implikasi dari penelitian ini adalah diharapkan pemerintah dapat meningkatkan kepercayaan dari masyarakat sehingga motivasi pembayaran pajak bukan karena power tetapi karena adanya trust kepada pemerintah. Peneliti menyarakan agar responden diberikan penghargaan karena telah meluangkan waktu untuk mengisi kuesioner. Selain itu juga untuk meningkatkan respon rate bagi penelitian berikutnya.

\section{DAFTAR PUSTAKA}

Abdullah, I., \& Nainggolan, E. P. (2018). Pengaruh Pengetahuan Wajib Pajak, Kesadaran Wajib Pajak Terhadap Motivasi Membayar Pajak Dengan Penerapan UU Tax Amnesty Sebagai Variabel Moderating Pada KANWIL DJP SUMUT I MEDAN. Liabilities Jurnal Pendidikan Akuntansi, 1(2), 181191.

Caroko, B. (2015). Pengaruh pengetahuan perpajakan, kualitas pelayanan pajak dan sanksi pajak terhadap motivasi wajib pajak orang pribadi dalam membayar pajak. Jurnal Mahasiswa Perpajakan, 4(1).

Cimberly, P., Manossoh, H., \& Wokas, H. R. (2018). Pengaruh Pengetahuan Perpajakan Dan Kualitas Pelayanan Pajak Terhadap Motivasi Dalam Membayar Pajak Penghasilan (Studi Pada Wpop Di Kec. Wanea Kota Manado). Going Concern: Jurnal Riset Akuntansi, 13(04).

Dalimunthe, M. I. (2018). Pengaruh Persepsi Yang Baik Tentang Sistem Perpajakan, Motivasi Dan Sanksi Terhadap Kepatuhan Wajib Pajak Orang 
Firda Ayu Amalia : Slippery Slope Framework: Motivasi Pembayaran Pajak Dan Kepatuhan Pajak

Pribadi Dalam Membayar Pajak Pada KPP Pratama Medan Belawan. KITABAH: Jurnal Akuntansi dan Keuangan Syariah.

Damayanti, T. W., \& Martono, S. (2018). Taxpayer compliance, trust, and power. Jurnal Keuangan dan Perbankan, 22(2), 231-239.

DJP. (2018). Peningkatan Kesadaran dan Kepatuhan Wajib Pajak Pelaku UMKM. Jakarta: Kementrian Keuangan Retrieved from https://www.pajak.go.id/sites/default/files/201911/Laporan\% 20Tahunan\%20DJP\% 202018\%20\%20bahasa \%20Indonesia.pdf.

Fauziah, U., \& Tidajoh, B. E. (2018). Perencanaan Pajak Untuk Usaha Mikro, Kecil, Dan Menengah. Substansi: Sumber Artikel Akuntansi Auditing dan Keuangan Vokasi, 2(2), 200-214.

Ghozali, I., \& Latan, H. (2015). Partial Least Squares, konsep, teknik dan aplikasi menggunakan program Smartpls 3.0 untuk penelitian empiris. Semarang: Badan Penerbit UNDIP.

Hartono, J., \& Abdillah, W. (2009). Konsep dan Aplikasi PLS (Partial Least Square) Untuk Penelitian Empiris. Edisi I, BPFE, Yogyakarta.

Kastlunger, B., Lozza, E., Kirchler, E., \& Schabmann, A. (2013). Powerful authorities and trusting citizens: The Slippery Slope Framework and tax compliance in Italy. Journal of Economic psychology, 34, 36-45.

Kemenkeu. (2018). APBN Kita Kinerja dan Fakta. Jakarta: Kementrian Keuangan Retrieved from https://www.kemenkeu.go.id/media/11284/apbn-kitaedisi-desember-2018.pdf.

Khasanah, U., Sutrisno, T., \& Mardiati, E. (2019). Coercive Authority and Trust in Tax Authority in Influencing Voluntary Tax Compliance: A Study of Slippery Slope. Journal of Accounting and Investment, 20(1), 75-93.

Kirchler, E., Hoelzl, E., \& Wahl, I. (2008). Enforced versus voluntary tax compliance: The "slippery slope" framework. Journal of Economic psychology, 29(2), 210-225.

Mangoting, Y., \& Sadjiarto, A. (2013). Pengaruh postur motivasi terhadap kepatuhan wajib pajak orang pribadi. Jurnal Akuntansi dan Keuangan, 15(2), 106-116.

Mas' ud, A., Abd Manaf, N. A., \& Saad, N. (2019). Trust and power as predictors of tax compliance: global evidence. Economics $\mathcal{E}$ Sociology, 12(2), 192-204.

Movanita, A. N. K. (2019). Dari Hampir 60 Juta UMKM, Baru 1,8 Juta Terdaftar sebagai Wajib Pajak. Kompas. Retrieved from https://money.kompas.com/read/2019/04/30/153718726/dari-hampir$\underline{60 \text {-juta-umkm-baru-18-juta-terdaftar-sebagai-wajib-pajak?page }=\text { all }}$ 
Firda Ayu Amalia : Slippery Slope Framework: Motivasi Pembayaran Pajak Dan Kepatuhan Pajak

Mustofa, F. A. (2016). Pengaruh Pemahaman Peraturan Perpajakan, Tarif Pajak Dan Asas Keadilan Terhadap Kepatuhan Wajib Pajak (Studi pada Wajib Pajak Usaha Mikro Kecil dan Menengah yang Berada Di Wilayah Kerja Kantor Pelayanan Pajak Pratama Batu Setelah Diberlakukannya Peratu. Jurnal Mahasiswa Perpajakan, 8(1).

Septyani, A. E., Sudiartana, I. M., \& Mahaputra, I. N. K. A. (2020). Pengaruh Kualitas Pelayanan, Pemahaman Wajib Pajak Dan Penurunan Tarif Pajak Penghasilan Final Terhadap Kepatuhan Pembayaran Pajak Pelaku Usaha Mikro, Kecil Dan Menengah (Umkm) Di Kota Denpasar. Kumpulan Hasil Riset Mahasiswa Akuntansi (KHARISMA), 2(2), 372-392.

Simanjuntak, O. D. P., \& Sucipto, T. N. (2018). Pengaruh Motivasi Membayar Pajak Terhadap Kepatuhan Wajib Pajak Orang Pribadi Di Kantor Pelayanan Pajak Ratama Medan Petisah. Jurnal Mutiara Akuntansi, 3(2), 25-33.

Sularsih, H. (2018). Dampak Penerapan Peraturan Pemerintah No 23 Tahun 2018 Terhadap Peningkatan Pajak Umkm Di Kota Malang. JAMSWAP, 3(3), 18.

Tatik, T. (2018). Potensi Kepatuhan Pembayaran Pajak Pada Pelaku Umkm (Usaha Mikro Kecil Dan Menengah) Pasca Penerbitan Peraturan Pemerintah Nomor 23 TAHUN 2018 (Studi Kasus Pada UMKM di Kabupaten Sleman-Yogyakarta). Sustainable Competitive Advantage (SCA), $8(1)$. 